\section{Paracetamol: a probably still safe drug}

In a recent meta-analysis, Roberts and coworkers have raised several concerns about the safety profile of paracetamol. ${ }^{1}$ The criticism was supported by a clear association between exposure and risk of major end points (all-cause mortality, cardiovascular disease (CVD), hypertension, gastrointestinal (GI) disorders, renal failure) and a clear demonstration of a dose-response effect. Although Roberts's message is not conclusive-authors themselves suggest the need of further meta-analyses-it surely has a relevant burden in terms of public health being paracetamol the most largely used drug as first-line therapy for pain disorders.

We present a critical revision of Roberts's meta-analysis following a step-by-step analytical approach.

First, the quality of cohort studies included in the meta-analysis is overtly and intrinsically low.

The authors broadly ascribe the low degree of internal validity of studies collected for the meta-analysis using the GRADE method, ${ }^{2}$ although this tool is likely unsuitable for quality assessment of non-experimental studies. ${ }^{1}$

Instead, we adopted the Cochrane A Cochrane Risk Of Bias Assessment Tool (ACROBAT) checklist, which is specifically tailored on observational investigations. ${ }^{3}$ By doing so, we identified several major methodological pitfalls among the collected studies (table 1).

Second, most of the discussed examples fail to demonstrate a convincing dose-response effect.

A clear dose-response effect was only revealed for the increased incidence of hypertension estimated by two severely biased studies based on Nurse's Health Study cohort ${ }^{5}$ (see the following paragraphs for the details). Notably, Roberts and coworkers support the presence of a dose-response gradient for studies where this relation was instead represented by a plateau (outcome: mortality $^{6}$ ); by a U-shaped curve (outcome: mortality, ${ }^{7}$ GI haemorrhage $\left.^{7}\right)$; by an ascending trend followed by a clamorous final reverse (outcome: renal failure, ${ }^{8}$ hypertension ${ }^{9}$ ) and by a wavering and/or confusing relations (outcome: myocardial infarction, stroke, $^{7}$ renal failure ${ }^{70}$ ). In addition, some of these trends-by admission of the same authors ${ }^{6}{ }^{7}$-were also due to uncorrected confounding bias, namely confounding by indication.

Third, every bias potentially afflicting the paracetamol research is poorly discussed.

We briefly resume our consideration for each individual outcome.

All-cause mortality: Roberts's results likely suffer from confounding bias in particular confounding by indication due to patients' prognosis. Paracetamol tends to be preferentially assigned to sicker and frailer patients, whose prognosis is likely worse; the effect of this confounder is easily explained by temporal trends of mortality rates. In Lipworth's research, ${ }^{6}$ the standardised mortality ratios peak in the first year of follow-up as well as the crude mortality rates observed by De Vries's. ${ }^{7}$ In essence, sicker patients assigned to paracetamol died sooner only because of the worse basal prognosis.

Hypertension: Two investigations performed using the Nurse's Health Study cohort ${ }^{4} 5$ represent a classic didactic example of uncorrected detection bias. The outcome was in fact recorded through biennial questionnaires and the diagnosis of hypertension was made by patient's physicians. The pain-affected patients are therefore featured by a greater likelihood to see their doctors, received more prescriptions of analgesics and more diagnoses of hypertension.
Roberts and coworkers carried out for this end point their unique meta-analytical calculation. Our reanalysis clearly shows the presence of publication bias and/or distortions attributable to biased studies, which have been collected (figure 1). Indeed, both these issues explain the asymmetry of the funnel-plot distribution, which is particularly relevant in the presence of few units of analysis - as is the case-where the statistical power for testing the presence of publication bias is low. ${ }^{2}$

CVD: Chan's research ${ }^{4}$ was involved into the Nurse's Health Study cohort as well. Non-exposed patients are characterised by a longer duration of follow-up (13 years), whereas the paracetamol users showed a CVD risk proportional to both level of exposure and mean duration of follow-up. In other words, the observation time was stopped in that research: for censoring or for having the outcome at lower and the upper levels of exposure, respectively. Surprisingly, no missing data were reported for the overall 12 years of follow-up.

All data included in Chan's analyses (ie, exposure, outcome, covariates) were collected from last update (ie, from the last biennial questionnaire), so indicating the adjustment was made for variables potentially changed after the exposure to paracetamol. This analytical method is generally not appropriate, ${ }^{3}$ and authors do not offer sufficient details about it.

CVD end points were also considered by the study of De Vries t $^{\mathrm{al}} \mathrm{l}^{7}$ : in spite of the lot of covariates used in the regression models, the authors do not adjust for the concomitant use of other analgesics, making the results highly vulnerable to effect of important confounders (eg, use of COX-2 inhibitors). The De Vries study, as admitted by the same author, can be burdened by protopathic bias as well. Namely, the exposure to analgesics may have been justified by symptoms arising right before the diagnosis, being in that manner the outcome antecedent to the exposure. ${ }^{11}$ Not surprisingly, the risk of myocardial infarction in that study is maximum with the first ever use of paracetamol.

GI end points: This outcome was only studied in the research of De Vries $e t \mathrm{al}^{7}$ and surely suffers from confounding by indication due to patients' prognosis. As for mortality, the doseresponse relationship was indeed U-shaped. Of note, there were no case-control studies (whose quality was generally better with respect to included cohort studies-data not shown), among those excluded by Roberts's meta-analysis, to show some detrimental effect of paracetamol on GI system. ${ }^{12-17}$

Renal end points: Two investigations support a kind of kidney damage associated to paracetamol use, ${ }^{78}$ while the other two do not. ${ }^{10} 18$ Surprisingly, Roberts supports a detrimental effect for Kurth's results, in overt contrast with the conclusions of the same author ("acetaminophen...does not appear to increase the risk for decline in kidney function"10). This is also the case where observational research on paracetamol might be seriously burdened by confounding by indication, channelling bias and protopathic bias. ${ }^{11}$ Paracetamol represents generally the first analgesic choice in patients with early signs of renal failure, being in that manner the use of that drug spuriously associable to a greater risk of kidney damage (confounding by indication). At the same time, in the presence of first renal damage, patients earlier exposed to non-steroidal anti-inflammatory drugs (NSAIDs) are frequently shifted to paracetamol use (channelling bias: the use of drugs with similar indications is therefore conditioned by the nature of the end point). Finally, the formerly described protopathic bias can assume in renal disease a particular relevance. ${ }^{11} 19$ On this respect, De Vries reported a bigger risk of acute renal failure for current users of paracetamol in comparison to past users. Furthermore, this study was not 


\begin{tabular}{|c|c|c|c|c|c|c|c|c|c|c|c|c|}
\hline & $\begin{array}{l}\text { Mortality } \\
(\text { Lipworth } \\
\left.\text { et al } l^{6}\right)\end{array}$ & $\begin{array}{l}\text { Mortality } \\
\text { (De Vries } \\
\left.\text { et } a l^{\prime}\right)\end{array}$ & $\begin{array}{l}\text { CVD end } \\
\text { point }(\text { Chan } \\
\left.\text { et } a l^{4}\right)\end{array}$ & $\begin{array}{l}\text { Myocardial } \\
\text { Infarction (De } \\
\left.\text { Vries et } a l^{D}\right)\end{array}$ & $\begin{array}{l}\text { Stroke }(\mathrm{De} \\
\left.\text { Vries et } \mathrm{al}^{7}\right)\end{array}$ & $\begin{array}{l}\text { Hypertension } \\
\text { (Curhan et } a l^{8} \text { ) }\end{array}$ & $\begin{array}{l}\text { Hypertension } \\
\left.\text { (Dedier et } a l^{9}\right)\end{array}$ & $\begin{array}{l}\text { Upper GI } \\
\text { events (De } \\
\left.\text { Vries et } a l^{7}\right)\end{array}$ & $\begin{array}{l}\text { Acute kidney } \\
\text { failure }(D e \\
\left.\text { Vries et } a l^{7}\right)\end{array}$ & $\begin{array}{l}\text { Chronic } \\
\text { kidney } \\
\text { failure } \\
\text { (Curhan } \\
\text { et } a l^{8} \text { ) }\end{array}$ & $\begin{array}{l}\text { Chronic } \\
\text { kidney failure } \\
\text { (Kurth et } a l^{10} \text { ) }\end{array}$ & $\begin{array}{l}\text { Chronic } \\
\text { kidney } \\
\text { failure } \\
\text { (Evans } \\
\left.\text { et al }{ }^{18}\right)\end{array}$ \\
\hline \multicolumn{13}{|l|}{ Bias type } \\
\hline $\begin{array}{l}\text { Bias due to } \\
\text { confounding }\end{array}$ & Critical & Critical & Critical & Critical & Critical & Low & Low & Critical & Critical & Serious & Low & Serious \\
\hline $\begin{array}{l}\text { Bias in selection of } \\
\text { participants into } \\
\text { the study }\end{array}$ & Moderate & Low & Low & Low & Low & Moderate & Low & Low & Low & Low & Moderate & Serious \\
\hline $\begin{array}{l}\text { Bias in } \\
\text { measurement of } \\
\text { intervention }\end{array}$ & NA & Moderate & Low & Moderate & Moderate & Low & Low & Moderate & Moderate & Low & Low & Moderate \\
\hline $\begin{array}{l}\text { Bias due to } \\
\text { departure from } \\
\text { intended } \\
\text { interventions }\end{array}$ & $\begin{array}{l}\text { No } \\
\text { information }\end{array}$ & Serious & Serious & Serious & Serious & Moderate & Low & Serious & Serious & Moderate & Serious & Moderate \\
\hline $\begin{array}{l}\text { Bias due to missing } \\
\text { data }\end{array}$ & $\begin{array}{l}\text { No } \\
\text { information }\end{array}$ & $\begin{array}{l}\text { No } \\
\text { information }\end{array}$ & $\begin{array}{l}\text { No } \\
\text { information }\end{array}$ & No information & $\begin{array}{l}\text { No } \\
\text { information }\end{array}$ & Moderate & Low & No information & No information & Low & No information & Low \\
\hline $\begin{array}{l}\text { Bias in } \\
\text { measurement of } \\
\text { outcomes }\end{array}$ & $\begin{array}{l}\text { No } \\
\text { information }\end{array}$ & $\begin{array}{l}\text { No } \\
\text { information }\end{array}$ & Serious & No information & $\begin{array}{l}\text { No } \\
\text { information }\end{array}$ & Serious & Serious & No information & No information & Low & Serious & Low \\
\hline $\begin{array}{l}\text { Bias in selection of } \\
\text { reported results }\end{array}$ & Low & Moderate & Serious & Moderate & Moderate & Serious & Low & Moderate & Moderate & Moderate & Low & Moderate \\
\hline Overall & Critical & Critical & Critical & Critical & Critical & Serious & Serious & Critical & Critical & Serious & Moderate & Serious \\
\hline \multicolumn{13}{|c|}{ ACROBAT, A Cochrane Risk Of Bias Assessment Tool; CVD, cardiovascular disease; GI, gastrointestinal. } \\
\hline
\end{tabular}




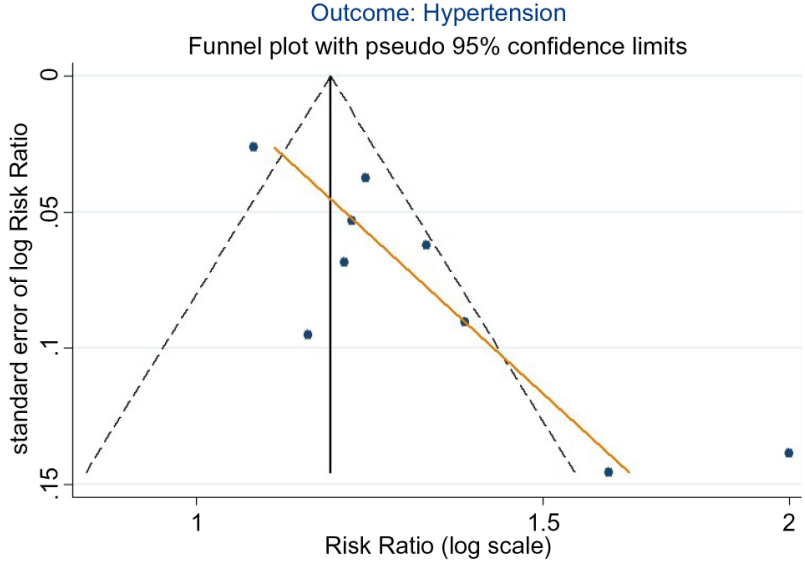

Figure 1 Funnel plot-outcome: risk of hypertension. The asymmetry of the risk ratio distribution can be attributed both to serious publication bias (Egger test $p=0.006$ ) and to seriously biased results at study level. ${ }^{2}$

adjusted for concomitant use of NSAIDs, which is an important risk factor for acute renal failure. ${ }^{20}{ }^{21}$ Curhan's research, ${ }^{8}$ included in the Nurse's Heath Study cohort as well, compared the renal function measured in two blood samples (1989 and $2000)$ in a small group of nurses $(n=1697)$ whose exposure to paracetamol was retrospectively explored in 1999. Obviously, an initial decline of renal function diagnosed in the range of time between the first and second blood sampling could have been influenced by both confounding by indication and channelling bias, not avoidable by regression adjustment made in that research.

\section{CONCLUSIONS}

Risk of bias in Roberts's research appears relevant to consent a valid warning about the safety profile of paracetamol, a drug used since 1877 and actually included in the WHO Model List of Essential Medicines. ${ }^{22}$ Provided that the systematic review of this meta-analysis might be exhaustive, it should be also observed that the quality of available information on this topic is still scarce. Good quality observational studies are therefore needed in attempt to minimise the many types of bias potentially influencing the paracetamol safety research.

\section{Alessandro Battaggia, ${ }^{1}$ Pierangelo Lora Aprile, ${ }^{1}$ lacopo Cricelli, ${ }^{2}$ Diego Fornasari, ${ }^{3}$ Andrea Fanelli, ${ }^{4}$ Claudio Cricelli, ${ }^{1}$ Francesco Lapi ${ }^{2}$ \\ ${ }^{1}$ Italian College of General Practitioners and Primary Care, Florence, Italy ${ }^{2}$ Health Search, Italian College of General Practitioners and Primary Care, Florence, Italy \\ ${ }^{3}$ Department of Medical Biotechnology and Translational Medicine, University of Milan, Milan, Italy \\ ${ }^{4}$ Unit of Anesthesiology and Pain Therapy, General Hospital S. Orsola Malpighi, University Hospital of Bologna, Bologna, Italy}

Correspondence to Dr Francesco Lapi, Research Director, Health Search, Italian College of General Practitioners and Primary Care, Via Sestese 61, Florence 50141, Italy; lapi.francesco@simg.it

Contributors All authors fulfil the International Committee of Medical Journal Editors (ICMJE) criteria for authorship credit. AB collected, analysed, interpreted the data, and drafted the manuscript. PLA interpreted the data and edited the manuscript. IC provided management support to research team and edited the article. DF contributed to writing and editing the manuscript. AF contributed to data interpretation and edited the manuscript. CC contributed to data interpretation and edited the manuscript. FL collected and interpreted the data and contributed to writing the manuscript.

Funding This work was supported by the Italian College of General Practitioners and Primary Care.
Competing interests $\mathrm{FL}$ and IC provided consultancies in protocol preparation for epidemiological studies and data analyses for IBSA and Angelini. CC and PLA provided clinical consultancies for IBSA, Angelini, Grunenthal, Alfa Wasserman, Pfizer, Prostrakan, Molteni, Dompè and Teva. AF provided clinical consultancies for IBSA. AB and DF have no conflict of interest to disclose.

Provenance and peer review Not commissioned; internally peer reviewed.

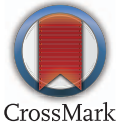

To cite Battaggia A, Lora Aprile P, Cricelli I, et al. Ann Rheum Dis 2016:75:e57.

Received 14 April 2016

Accepted 15 April 2016

Published Online First 10 May 2016

Ann Rheum Dis 2016;75:e57. doi:10.1136/annrheumdis-2016-209713

\section{REFERENCES}

1 Roberts E, Delgado Nunes V, Buckner S, et al. Paracetamol: not as safe as we thought? A systematic literature review of observational studies. Ann Rheum Dis 2016;75:552-9.

2 Higgins JPT, et al. Cochrane handbook for systematic reviews of interventions. Wiley-Blackwell, 2011.

3 Higgins JPT, Reebes BC, on behalf of the development group for ACROBAT - NRSI A Cochrane Risk Of Bias Assessment Tool: forn N.on-Randomized Studies of Interventions (ACROBAT - NRSI) 2014. http://www.riskofbias.info (accessed 11 Dec 2015).

4 Chan AT, Manson JE, Albert CM, et al. Nonsteroidal antiinflammatory drugs, acetaminophen, and the risk of cardiovascular events. Circulation 2006;113:1578-87.

5 Curhan GC, Willett WC, Rosner B, et al. Frequency of analgesic use and risk of hypertension in younger women. Arch Intern Med 2002;162:2204-8.

6 Lipworth L, Friis S, Mellemkjær L, et al. A population-based cohort study of mortality among adults prescribed paracetamol in Denmark. J Clin Epidemiol 2003; 56:796-801.

7 de Vries F, Setakis E, van Staa TP. Concomitant use of ibuprofen and paracetamol and the risk of major clinical safety outcomes. $\mathrm{Br} J$ Clin Pharmacol 2010;70:429-38

8 Curhan GC, Knight EL, Rosner B, et al. Lifetime nonnarcotic analgesic use and decline in renal function in women. Arch Intern Med 2004;164:1519-24.

9 Dedier J, Stampfer MJ, Hankinson SE, et al. Nonnarcotic analgesic use and the risk of hypertension in US women. Hypertension 2002;40:604-8; discussion 601-3.

10 Kurth T, Glynn RJ, Walker AM, et al. Analgesic use and change in kidney function in apparently healthy men. Am J Kidney Dis 2003:42:234-44.

11 Signorello LB, McLaughlin JK, Lipworth L, et al. Confounding by indication in epidemiologic studies of commonly used analgesics. Am J Ther 2002;9:199-205.

12 Lanas A, Serrano P, Bajador E, et al. Risk of upper gastrointestinal bleeding associated with non-aspirin cardiovascular drugs, analgesics and nonsteroidal anti-inflammatory drugs. Eur J Gastroenterol Hepatol 2003;15:173-8.

13 Blot WJ, McLaughlin JK. Over the counter non-steroidal anti-inflammatory drugs and risk of gastrointestinal bleeding. J Epidemiol Biostat 2000;5:137-42.

14 Langman MJS, Weil J, Wainwright $P$, et al. Risks of bleeding peptic ulcer associated with individual non-steroidal anti-inflammatory drugs. Lancet 1994;343:1075-8.

15 Laporte JR, Carné X, Vidal X, et al. Upper gastrointestinal bleeding in relation to previous use of analgesics and non-steroidal anti-inflammatory drugs. Catalan Countries Study on Upper Gastrointestinal Bleeding. Lancet 1991;337:85-9.

16 Levy M, Miller DR, Kaufman DW, et al. Major upper gastrointestinal tract bleeding. Relation to the use of aspirin and other nonnarcotic analgesics. Arch Intern Med 1988;148:281-5

17 Kaufman DW, Kelly JP, Sheehan JE, et al. Nonsteroidal anti-inflammatory drug use in relation to major upper gastrointestinal bleeding. Clin Pharmacol Ther 1993:53:485-94.

18 Evans M, Fored CM, Bellocco R, et al. Acetaminophen, aspirin and progression of advanced chronic kidney disease. Nephrol Dial Transplant 2009;24:1908-18.

19 Fored CM, Ejerblad E, Lindblad P, et al. Acetaminophen, aspirin, and chronic renal failure. N Engl J Med 2001;345:1801-8.

20 Pérez Gutthann S, García Rodríguez LA, Raiford DS, et al. Nonsteroidal anti-inflammatory drugs and the risk of hospitalization for acute renal failure. Arch Intern Med 1996;156:2433-9.

21 Griffin MR, Yared A, Ray WA. Nonsteroidal antiinflammatory drugs and acute renal failure in elderly persons. Am J Epidemio/ 2000;151:488-96.

22 World Health Organization (WHO). Hepatitis C, update to April 2014. http://www. who.int/mediacentre/factsheets/fs164/en/ (accessed Apr 2015). 